\title{
Preparedness of members of the Indonesian emergency and disaster nurses association
}

\author{
Guruh Suprayitno $^{1}$, Ahsan ${ }^{2}$, Karyono Mintaroem ${ }^{3}$ \\ ${ }^{1,2}$ Nursing Masters Study Program, Universitas Brawijaya, Indonesia \\ ${ }^{3}$ Faculty of Medicine, Universitas Brawijaya, Indonesia
}

\begin{tabular}{l}
\hline \hline Article Info \\
\hline Article history: \\
Received Jun 2, 2020 \\
Revised Aug 3, 2020 \\
Accepted Sep 11, 2020 \\
\hline
\end{tabular}

Keywords:

Disaster

Emergency nurses

Preparedness

\begin{abstract}
Disaster is a global issue all around the world, and Indonesia has shifted its disaster mitigation strategies from emergency response to disaster management preparedness. This research analysed factors influencing the preparedness of members of the Indonesian emergency and disaster association (IEDNA) in the face of natural disasters in Indonesia. This research is analytical-observational with a cross-sectional approach. Sampling was performed on a population of 510 member nurses of the IEDNA by the probability sampling technique. Out of the 510 member nurses of the IEDNA, 107 were enrolled in this research. The Fisher's exact test results show that knowledge had $\mathrm{p}=0.001(\mathrm{p}<0.05)$, while facilities and infrastructures availability $\mathrm{p}=0.000(\mathrm{p}<0.05)$, in their effects on nurse preparedness. The multivariate analysis yielded $\operatorname{Exp}(\mathrm{B})$ of 0.022 for knowledge and $\operatorname{Exp}(\mathrm{B})$ of 0.003 for facilities and infrastructures availability, while the Nagelkerke's R-squared obtained was 66\%. The variable preparedness was largely good, and there were significant relationships of knowledge and facilities and infrastructures availability to the preparedness of members of the IEDNA. The strongest factor was knowledge.
\end{abstract}

This is an open access article under the CC BY-SA license.

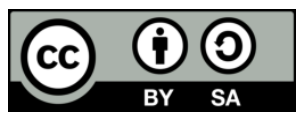

\section{Corresponding Author:}

Guruh Suprayitno,

Nursing Master Study Program,

Universitas Brawijaya,

Jalan Veteran, Ketawanggede, Distric of. Lowokwaru, Malang city 65145, East Java, Indonesia.

Email: suprayitno.guruh@gmail.com

\section{INTRODUCTION}

Disaster becomes a problem of the whole world due to its complexity and need for mitigation. Disaster mitigation encompasses good planning and arrangement that will allow for directed and integrated implementation. All countries across the globe are potentially at risk of natural disaster. Indonesia is a country prone to catastrophic events for its geological characteristics with active volcanoes and geological faults, placing it at risk of earthquakes, landslides, tsunamis, and floods. Active tectonic plates also run through the territory, for example, the Eurasian Plate, Indo-Australian Plate, and underlying Pacific Plate [1,2].

Vulnerability to calamity in Indonesia has shifted the disaster mitigation strategies from emergency response to disaster management preparedness, and this becomes the cross-sectorial responsibilities of the Government, non-governmental organizations, and the society along with health care providers, notably the nurse [3, 4] as a principal part of disaster preparedness [5]. According to Melnikov, Itzhaki, and Kagan, nurses' preparedness is influenced by three factors, namely, the nurses' knowledge regarding disaster, realistic judgment of disaster, and self-efficacy to perform preparedness [6]. Further, Phetrico and 
Loerzus argue that facilities and infrastructures availability and government policies influence nurses' preparedness [7]. Besides, Mondargue and Lircones proved that nurses' individual factors also affect their preparedness in facing disaster, namely, knowledge and attitude [8]. Meanwhile, Veenema et al., pointed out that, in principle, nurses' preparedness in facing disaster is determined by individual and organizational resource factors, where the former includes matters pertaining to the nurses' individual capacity such as knowledge and attitude, while the latter refers to the supporting factors available in the institutions in which the nurses work, for instance, facilities and infrastructures [5].

The nurses' preparedness will be good if the nurses' knowledge and education in relation to preparedness are also good. In other words, the knowledge factor is inseparable from nurses' preparedness [9]. Excellent disaster mitigation will be able to reduce loss of life, asset, or other things [10, 11]. Nurses should have an understanding of the aforementioned, although, in some cases, they might poorly understand their own roles both during the disaster preparedness phase and when handling the situation following a disaster [4]. Of several factors potentially influencing nurses' preparedness in facing disaster, two became a focus of this research, namely, knowledge and availability of disaster mitigation facilities and infrastructures. This research intended to analyze the factors influencing the preparedness of members of the Indonesian emergency and disaster nurses association (IEDNA) in facing natural disasters in Indonesia.

\section{RESEARCH METHOD}

This research is analytical-observational with a cross-sectional approach [12]. The participants were nurses working at the hospital, educational institution and community health centre and they are members of the Indonesian emergency and disaster nurses association (IEDNA). This research involved six Indonesian provinces affected by natural disasters since 2004 until 2019, namely, the provinces of Aceh, Banten, Special Region of Yogyakarta, Central Sulawesi, West Nusa Tenggara, and Papua. The data collection employed Google Forms, and prospective respondents, sampled by the probability sampling technique [13], were required to fill out the forms of consent before completing the questionnaires. The inclusion criteria of this research were that the nurses were working or had worked at health care institutions or education institutions in the field of emergency and that they were registered as members of the IEDNA. This survey was previously performed on several IEDNA nurses in East Java to ensure the instrument reliability.

Research data were collected by three questionnaires of the knowledge, availability of facilities and infrastructures, and preparedness of IEDNA nurses in facing disasters in Indonesia. The 9-question knowledge questionnaire was adopted from the guide of the Research Centre for Oceanography of the Indonesian Institutes of Sciences on the society and school community's level of preparedness measurement [14] with a Cronbach's alpha of 0.721 . The 18-question questionnaire of the nurses' perception on facilities and infrastructures availability was adopted from Regulation of the Minister of Home Affairs No. 27 of 2007 on the Guide to Facilities and Infrastructures Preparation for Disaster Mitigation [15], which used a five-point Likert scale with the following criteria: 5 for "strongly agree," 4 for "agree," 3 for "neither agree nor disagree," 2 for "disagree," and 1 for "strongly disagree." The questionnaire had a Cronbach's alpha of 0.768. Lastly, the 33-question nurses' preparedness questionnaire adopted the Japanese Disaster Nursing Readiness Evaluation Index developed by Maeda, Kotera, Matsuda, and Huebner, (2018), using a four-point Likert scale with the following criteria: 4 for "always," 3 for "frequently," 2 for "occasionally," and 1 for "never" [16]. The last questionnaire was translated from English to Indonesian by a professional translator and expert in the field of disaster nursing, with a Cronbach's alpha of 0.739, the statistical test for analyzing the relationship of knowledge and facilities and infrastructures availability to the preparedness of IEDNA members used a Fisher's exact test at a 95\% significance level [17]. This research was granted a letter of ethical feasibility from the Medical Research Ethics Committee of the Faculty of Medicine, Universitas Mataram, No. 33/UN18.F7/ETIK/2020.

\section{RESULTS AND DISCUSSION}

Out of 510 nurses, 107 participated in this research and met the inclusion criteria. Table 1 show that most of the respondents were male and of the age ranges of 31-40 years. The respondents were majorly graduates of nursing or medicine Bachelor's degree programs, of married status, and in service at the emergency department (ED). The best part of the respondents had been working as nurses for 10-20 years and had been performing emergency services for $<1$ year and between 1-5 years as shown in Tabel 1 . Table 2 shows that nearly all respondents agreed that nurses have a role in not only the disaster preparedness phase, but also in the response and post-disaster phases.

Table 3 shows that most of the respondents had a good level of knowledge and preparedness to face disaster. Based on the Fisher's exact test result, H0 was rejected, meaning that there was a significant 
relationship between knowledge and IEDNA nurses' preparedness. Similarly, Table 4 shows that most of the respondents had well the availability of facilities and infrastructures for facing disaster. The Fisher's exact test result statistically suggests that $\mathrm{HO}$ should be rejected, meaning that there was a significant relationship between the perception on facilities and infrastructures availability and the preparedness of IEDNA nurses in Indonesia.

Table 1. Characteristics of demographic

\begin{tabular}{|c|c|c|c|}
\hline No & Characteristics & $\mathrm{n}$ & $\%$ \\
\hline \multirow[t]{4}{*}{1} & Gender & & \\
\hline & Male & 60 & 56.1 \\
\hline & Female & 47 & 43.9 \\
\hline & Total & 107 & 100.0 \\
\hline \multirow[t]{6}{*}{2} & Age & & \\
\hline & $<30$ years & 36 & 33.6 \\
\hline & $31-40$ years & 50 & 46.7 \\
\hline & $41-50$ years & 17 & 15.9 \\
\hline & $>50$ years & 4 & 3.7 \\
\hline & Total & 107 & 100.0 \\
\hline \multirow[t]{5}{*}{3} & The highest level of education attained & & \\
\hline & Three-year vocational nursing education & 33 & 30.8 \\
\hline & Bachelor of Nursing/ Bachelor of Health Science & 60 & 56.1 \\
\hline & Master degree in nursing or health science & 14 & 13.1 \\
\hline & Total & 107 & 100.0 \\
\hline \multirow[t]{4}{*}{4} & Marital status & & \\
\hline & Married & 78 & 72.9 \\
\hline & Single & 29 & 27.1 \\
\hline & Total & 107 & 100.0 \\
\hline \multirow[t]{10}{*}{5} & Work Unit & & \\
\hline & Hospital & & \\
\hline & Emergency departments & 37 & 34.6 \\
\hline & Intensive Care Unit/High Care Unit & 10 & 9.3 \\
\hline & Operating theater & 2 & 1.9 \\
\hline & Renal Dialysis Unit & 1 & 0.9 \\
\hline & Ward & 27 & 25.2 \\
\hline & Educational Institution & 19 & 17.8 \\
\hline & Community health center & 11 & 10.3 \\
\hline & Total & 107 & 100.0 \\
\hline
\end{tabular}

Table 2. Nurses in the preparedness phase, response phase, and post-disaster phase

\begin{tabular}{cccc}
\hline No & Characteristic & $\mathrm{n}$ & $\%$ \\
\hline 1 & The Role of Nurses in the Preparedness (Pre-Disaster) Phase & & \\
& Yes & 101 & 94.4 \\
& No & 6 & 5.6 \\
& Total & 107 & 100.0 \\
& & & \\
2 & The Role of Nurses in the Disaster Response Phase & 104 & 97.2 \\
& Yes & 3 & 2.8 \\
& No & 107 & 100.0 \\
& Total & & \\
& & 102 & 95.3 \\
& The Role of Nurses in the Post-Disaster Phase & 5 & 4.7 \\
& Yes & 107 & 100.0 \\
\hline & No & & \\
& Total & &
\end{tabular}

Table 3. The results of fisher's test on relationship between knowledge and emergency and disaster nurses'

\begin{tabular}{cccccccc} 
& \multicolumn{7}{c}{ preparedness in Indonesia } \\
\hline \multirow{6}{*}{ Knowledge } & Poor & 5 & 50.0 & 6 & 6.2 & 15.167 & 0.001 \\
& Good & 5 & 50.0 & 91 & 93.8 & & \\
& Total & 10 & 100.0 & 97 & 100.0 & & \\
\hline
\end{tabular}

This research used a logistic regression analysis under the backward LR method. The Hosmer-Lemeshow test result suggests the reception of H0, meaning that the model was acceptable and that hypothesis testing was performable since no significant difference was found between the model and the observation value. Meanwhile, the Nagelkerke R-square value show that the variable preparedness could 
be explained by knowledge and facilities and infrastructures availability at $66 \%$ and by other factors outside the model investigated at $34 \%$. Based on the multivariate analysis result, knowledge had a stronger effect on IEDNA nurses' preparedness than facilities and infrastructures availability as shown in Table 5.

Table 4. The results of Fisher's test on relationship between the availability of facilities and infrastructures and emergency and disaster nurses' preparedness in Indonesia

\begin{tabular}{cccccccc}
\hline & & \multicolumn{2}{c}{ Emergency nurses' preparedness } & OR & p-value \\
& & $\mathrm{n}$ & $\%$ & $\mathrm{n}$ & $\%$ & & \\
\hline Facilities and & Poor & 6 & 60.0 & 1 & 1.0 & & \\
infrastructures availability & Good & 4 & 40.0 & 96 & 99.0 & 144.000 & 0.000 \\
& Total & 10 & 100.0 & 97 & 100.0 & & \\
\hline
\end{tabular}

Table 5. The results of multivariate analysis on relationship between knowledge, the availability of facilities and infrastructures and emergency and disaster nurses' preparedness in Indonesia

\begin{tabular}{cccccc}
\hline Variabel & $\mathrm{B}$ & $\mathrm{p}$-value & Exp(B) & $\begin{array}{c}\text { Hosmer and } \\
\text { Lemeshow test }\end{array}$ & $\begin{array}{c}\text { Nagelkerke } \\
\text { R square }\end{array}$ \\
\hline Knowledge & -3.823 & 0.002 & 0.022 & & 0.989 \\
Facilities and infrastructures availability & -5.910 & 0.000 & 0.003 & 0.660 \\
Constant & 4.511 & 0.000 & 90.987 & & \\
\hline
\end{tabular}

\subsection{Knowledge on disaster preparedness}

Knowledge is one of the components of predisposition factor that makes it easy for one to do something, or, in other words, it triggers the behavior of an individual, group, or society. It is one of the keys to the creation of an individual behavior, where behavior that arises on the basis of knowledge will usually remain in an individual longer than one which is not built upon knowledge [18]. As pointed out by Mondargue and Lircones, knowledge is among the factors that influence nurses' level of preparedness in facing and handling disaster $[8,19]$.

The result of the bivariate analysis between knowledge and nurses' preparedness in facing earthquake, tsunami and flood disaster indicates a significant relationship. The result shows that $97.2 \%$ of the nurses were of good knowledge. This agrees with the research by Ahayalimudin and Osman, which states that $80 \%$ of the nurses had good knowledge on disaster and how to manage it [20]. Hermawati et al., found that the nurses' knowledge and preparedness were at moderate levels [21]. This research also agrees with the research by Mary, which found the nurses' knowledge of disaster preparedness to be at a 55\% rate [22]. However, this research shows dissimilarities with the research by Seyedin et al., which found the nurses' knowledge of disaster preparedness as poor, and that by Ghanbari et al., which also found the average score of the nurses' disaster preparedness knowledge to below [23, 24]. It was also discovered in a separate study that emergency nurses lacked sufficient knowledge of disaster management [25].

According to Chen et al., knowledge is a factor that can shape preparedness in individuals, including nurses, in facing disaster [9]. Good knowledge in nurses is expected to form an appropriate mindset in executing disaster mitigation management, especially when it comes to preparedness. In the event of a disaster, a nurse is expected to act according to his/her role when assisting the patients and the person who visit the patient, hence preventing disaster impacts such as one on physical or mental health.

The research results show that $56.1 \%$ of the nurses held a Bachelor's degree in nursing. Nurses of a high level of education will have a more complex knowledge on disaster preparedness [9], which will help them make a quick, accurate decision on a program or public treatment necessary when a disaster strikes. IEDNA nurses' knowledge and preparedness were closely related. The nurses' preparedness would be good if their knowledge or education relating to preparedness was also good, suggesting that knowledge was indispensable to the nurses' preparedness. In addition to knowledge and education, experience in disaster management and training also have a significant effect on nurse preparedness in facing disasters [26, 27]. As held by Ahayalimudin et al., sufficiency of knowledge and practice can depict a positive attitude in an involvement with a disaster response [25]. From the nurses' knowledge, it can be concluded that good knowledge will give good preparedness too. It was concluded in this research then that knowledge has a relationship with nurses' preparedness in facing disasters in Indonesia.

\subsection{Availability of disaster management facilities and infrastructures}

The result of bivariate analysis between availability of facilities and infrastructures and emergency nurses' preparedness regarding natural disaster indicates a significant relationship. Facilities and 
infrastructures are a critical factor which is highly valuable to the preparedness of all elements, be it the people, the Government, or school community, in facing disaster. Adequate disaster mitigation facilities and infrastructures offer a high degree of ease in the preparation to face disaster, including the mitigation, preparedness, emergency response, evacuation, rehabilitation, and recovery. The nurses' preparedness in facing disaster is inseparable from the availability of facilities and infrastructures as all efforts that the nurses make, whether it is planning, disaster socialization for the community, disaster simulation, or health services for disaster victims, require facilities and infrastructures such as evacuation tools, modes of transportation, material and information delivery media, medical equipment as aid during a disaster [7]. Veenema et al., assert in their research article that the availability of facilities and infrastructures is one of the contributing factors that determines how good a nurse's preparedness is in facing disaster [28].

The Indonesian Government constantly makes efforts to provide disaster preparedness facilities and infrastructures. This is proven by Regulation of the Minister of Home Affairs No. 27 on the Guide to Facilities and Infrastructures Preparation in Disaster Mitigation, which makes a division into general facilities and infrastructures, consisting of 1) early warning system according to the condition and capacity of the region, 2) disaster posts along with supporting equipment, 3) operational vehicles according to the condition of the region, 4) disaster vulnerability map, 5) evacuation routes and locations, 6) fixed procedure, 7) public kitchens along with the logistics, 8) health posts with health personnel and medications, 9) emergency signs, 10) sanitation, 11) data collection equipment, and 12) temporary locations for evacuees, and special facilities, consisting of 1) media centers, 2) official spokespersons, 3) field hospitals along with health equipment support, 4) trauma centers, 5) local modes of transportation, and 6) mass graves for casualties [15]. Based on the description above, it can be concluded that the availability of facilities and infrastructures is also a crucial factor related to the preparedness of the emergency and disaster nurses in Indonesia in facing disaster. Therefore, it is important that IEDNA and health services complement training facilities and infrastructure and disaster management simulation to support the preparedness of emergency nurses in dealing with disasters in Indonesia.

\subsection{Preparedness of the emergency and disaster nurses in Indonesia}

The result of the coefficient of determination testing by a Nagelkerke R-squared in this research shows that the variables in this research exerted influence on the preparedness of the emergency and disaster nurses in Indonesia at $66 \%$, while the remaining $34 \%$ influence came from other factors. The researchers observed some other factors that could influence the preparedness of the IEDNA nurses, including planning, the society's level of education, nurse's level of stress, and communication. This is as reported by Ahmad, Ahsan and Fathoni, that $63.7 \%$ of the society never received any disaster preparedness knowledge or training, although if the society had an adequate knowledge of danger, vulnerability, risk, and disaster risk reduction activities, effective society action in facing disaster could be devised [29]. Maeda et al., mentioned six dimensions that can influence nurses' preparedness, namely, 1) communication skills for teamwork, 2) adaptability to stressful situations in a disaster location, 3) practical skills for disaster response, 4) emergency nursing skills, 5) cooperation skills, and 6) effective stress coping skills [16]. Another study also made a reference to four factors that can influence nurses' preparedness, namely, 1) critical thinking skills, 2) technical skills, 3) general diagnostics, and 4) communication skills [30].

\section{CONCLUSION}

This study reveals that the knowledge of most IEDNA nurses and the availability of disaster management facilities and infrastructure are in a good category. There was a significant relationship of knowledge and availability of facilities and infrastructures to IEDNA nurses' preparedness. Knowledge was the strongest factor in influencing preparedness of IEDNA nurses. The limitation of this research was that it only involved two independent variables-knowledge and facilities and infrastructures availability-as a focus. It can be recommended that future researchers should analyze other factors which affect the preparedness of emergency nurses in facing disasters, such as experience and training in disaster simulation.

\section{ACKNOWLEDGEMENTS}

The authors acknowledge Indonesian emergency and disaster nurses association (IEDNA) for their cooperation and facilitating during the entire process of the research.

\section{REFERENCES}

[1] E. Emaliyawati, A. Prawesti, I. Yosep, and K. Ibrahim, "Disaster Mitigation Management with Information Technology in Ciamis District," Padjdjaran Nurs. J., vol. 4, no. 1, pp. 79-88, 2016.

[2] L. J. Labrague, B. C. Yboa, D. M. M. Petitte, L. R. Lobrino, and M. G. B. Brennan, "Disaster Preparedness in Philippine Nurses," J. Nurs. Scholarsh., vol. 48, no. 1, pp. 98-105, 2016. 
[3] S. D. Oztekin, E. E. Larson, M. Akahoshi, and I. Oztekin, "Japanese nurses ' perception of their preparedness for disasters : Quantitative survey research on one prefecture in Japan,” Japan J. Nurs. Sci., vol. 13, pp. 391-401, 2016.

[4] M. Martono, S. Satino, N. Nursalam, F. Efendi, and A. Bushy, "Indonesian nurses' perception of disaster management preparedness," Chinese J. Traumatol., vol. 22, no. 1, pp. 41-46, 2019.

[5] T. G. Veenema et al., "Nurses as leaders in disaster preparedness and reponse a call to action," J. Nurs. Scholarsh., vol. 48, no. 2, pp. 187-200, 2017.

[6] S. Melnikov, M. Itzhaki, and I. Kagan, "Israeli Nurses ' Intention to Report for Work in an Emergency or Disaster," J. Nurs. Scholarsh., vol. 46, no. 2, pp. 134-142, 2014.

[7] L. G. Phetricco and B. Loerzus, "Government policies and infrastructure facilities on nurse preparedness for disaster," J. Disaster Manag., vol. 12, no. 1, pp. 9-21, 2016.

[8] Mondargue and Lircones, "Influence of individu factors with nurse preparedness level," J Disaster Manag., vol. 6, no. 1, pp. 9-20, 2015.

[9] H. Chen et al., "Nurse participation in continuing education in disaster nursing in taiwan," J. Emerg. Nurs., vol. 43, no. 3, pp. 197-202, 2017.

[10] ICN \& WHO, Framework of disaster nursing competencies, Geneva Switzerland: International Council of Nurses (ICN), 2009.

[11] Sujarwo, Noorhamdani, and M. Fathoni, "Disaster Risk Reduction in Schools : The Relationship of Knowledge and Attitudes Towards Preparedness from Elementary School Students in School-Based Disaster Preparedness in the Mentawai Islands, Indonesia,” Prehosp. Disaster Med., vol. 33, no. 6, pp. 581-586, 2018.

[12] Nursalam, "The Concept of Implementing Research Methods in Nursing Sciences," Jakarta: Salemba Medika, 2013.

[13] Sugiyono, "The Quantitative, Qualitative and R\&D Research Methods," Bandung: Alfabeta, 2016.

[14] I. Indonesian Institute of Sciences, "The Guide to Measure Community Preparedness and School Communities," LIPI, 2011.

[15] The Ministry of Home Affairs of the Republic of Indonesia, Regulation of the Minister of Home Affairs No. 27 of 2007 on the Guide to Facilities and Infrastructures Preparation for Disaster Mitigation, pp. 1-4, 2007.

[16] T. Maeda, S. Kotera, N. Matsuda, and C. A. Huebner, "Developing a scale to measure Japanese nurses' individual readiness for deployment to disasters," Nurs. Heal. Sci., vol. 20, no. 3, pp. 346-354, 2018.

[17] M. Dahlan, Statistics for Medicine and Health, 6th ed. Epidemiology of Indonesia, 2016.

[18] O. Arsenijević, D. Trivan, I. Podbregar, and P. Šprajc, "Strategic Aspect of Knowledge Management," Organizacija, vol. 50, no. 2, pp. 163-177, 2017.

[19] C. H. C. King, L. N. Spritzer, and L. N. Al-azzeh, "Perceived Knowledge, Skills, and Preparedness for Disaster Management Among Military Health Care Personnel," Mil. Med., pp. 1-7, 2019.

[20] N. A. Ahayalimudin and N. N. S. Osman, "Disaster management: Emergency nursing and medical personnel's knowledge, attitude and practices of the East Coast region hospitals of Malaysia," Australas. Emerg. Nurs. J., vol. 19 , no. 4 , pp. 1-7, 2016.

[21] D. Hermawati, U. Hatthakit, and A. Chaowalit, Nurses' preparedness of knowledge and skills in caring for patients attacked by tsunami in indonesia and its relating factors, 2010. [Online]. Available: kb.psu.ac.th/psukb/bitstream/2010/8531/1/341042.pdf

[22] E. Mary, "Emergency Nurses Readiness for Disaster Response - An Explorative Study," Am. Res. J. Nurs., vol. 4, no. 1, pp. 1-10, 2017.

[23] H. Seyedin, Z. A. Dolatabadi, and F. Rajabifard, "Emergency Nurses' Requirements for Disaster Preparedness," Trauma Mon, vol. 20, no. 4, pp. 2-4, 2015.

[24] V. Ghanbari, M. S.S, K. Khankeh, M. Karimloo, and A. Ardalan, "The Effect of a Disaster Nursing Education Program on Nurses' Preparedness for Responding to Probable Natural Disasters," Iran J. Nurs., vol. 24, no. 73, pp. 72-80, 2011.

[25] N. A. Ahayalimudin, A. Ismail, and I. M. Saiboon, "Disaster management: a study on knowledge, attitude and practice of emergency nurse and community health nurse," BMC Public Health, vol. 12, no. A3, p. 2458, 2012.

[26] H. Park and J. Kim, "Factors influencing disaster nursing core competencies of emergency nurses," Appl. Nurs. Res., pp. 1-22, 2017.

[27] D. Ansthobar and C. Miellen, Disaster Nursing Management. Delhi: Janpoor Company, 2013.

[28] T. G. Veenema et al., "Nurses as Leaders in Disaster Preparedness and Response-A Call to Action," J. Nurs. Scholarsh., vol. 48, no. 2, pp. 187-200, 2016.

[29] S. L. Ahmad, A. Ahsan, and M. Fathoni, "Factor Analysis Related To Family Preparedness Facing Disaster Impact In Ternate City of Maluku Utara Province," J. Ilmu Keperawatan, vol. 6, no. 1, pp. 108-123, 2018.

[30] G. Taskiran and U. Baykal, "Nurses ' disaster preparedness and core competencies in Turkey: a descriptive correlational design," Int. Nurs. Rev., vol. 66, no. 2, pp. 1-11, 2019.

Int. J. Public Health Sci, Vol. 9, No. 4, December 2020: 393 - 398 